\title{
O texto musical: considerações sobre manuscritos e edições eletrônicas
}

\author{
Ilza Nogueira* \\ Universidade Federal da Paraíba
}

\section{Resumo:}

Com base em dois estudos de caso - as partituras manuscritas de Jahrestraumzeiten (As 4 estações do sonho) e Sertania, Sinfonia do Sertão, do compositor Ernst Widmer -, o presente artigo discute a escrita musical manuscrita e eletrônica, avaliando quando uma e outra são mais efetivas à interpretação e, portanto, recomendáveis. As consideraçōes de Walter Ong em seu livro Orality and Literacy: The Technologizing of the Word - especificamente as que dizem respeito à reestruturação do pensamento pela escrita (à interiorização que a escrita estimula), de um lado, e ao aspecto reducionista da escrita (à perda de presença autoral na escrita), por outro lado - conduziram as reflexões aqui elaboradas.

Palavras-chave: texto musical; manuscritos hológrafos; edição musical eletrônica; notação iconográfica; Ernst Widmer

\footnotetext{
* Ilza Nogueira (PhD, State University of New York at Buffalo), é professora da Universidade Federal da Paraíba e atua também como Editor chefe do periódico Claves, do Programa de Pós-Graduação em Música. Sua obra teórica concerne à música contemporânea brasileira; com ênfase no Grupo de Compositores da Bahia. É autora do livro Ernst Widmer: perfil estilístico (Salvador: UFBA, 1997) e do Catálogo de Obras de Ernst Widmer publicado em 2007 pela Academia Brasileira de Música. Coordena o projeto de pesquisa "Marcos Históricos da Composição Contemporânea na UFBA", cujos produtos (edições musicais críticas, ensaios críticos e analíticos, e catálogos web), em formatos de e-books, estão disponibilizados para download em: <http:www.mhccufba.ufba.br.>. Desde 2003, Ilza Nogueira integra a Academia Brasileira de Música, ocupando a Cadeira 27.
} 


\section{Introdução}

Muito se discute a respeito das limitações da notação musical enquanto ferramenta para transmissão da concepção composicional; e freqüentemente temse dito que o texto musical ${ }^{1}$ é mera fonte de instruções para a recriação da música. Conseqüentemente, muito se tem valorizado o papel das fontes aurais e das informações verbais adicionais sobre obras e performances (de compositores, intérpretes, críticos e musicólogos) para a interpretação musical. Valer-se das convenções sígnicas para escrever música implica em submissão às tradições interpretativas implícitas no sistema de símbolos gráficos utilizado. A "oralidade" musical e o discurso verbal, portanto, atuam como guias auxiliares, tanto na concepção da notação quanto na compreensão da idéia que se esboça através dela. A escrita musical, per se, não transmite as idéias musicais do compositor; é a compreensão interpretativa do leitor de uma partitura ou do executante que concebe a idéia, a partir do seu nível de informação sobre o sistema sígnico utilizado e da sua bagagem cultural. A música executada, por conseguinte, reflete tanto o texto quanto a época e o local de procedência do intérprete; este, por sua vez, tenta refletir a época e o local de procedência do compositor. A execução de uma partitura escrita se resume, portanto, em reciclagem de conhecimento. Do fluxo e refluxo entre a música escrita e executada, deve-se o desenvolvimento de retóricas musicais ao longo da história da música nas diferentes culturas.

No século XX, viu-se como a multiplicidade de recursos sonoros e as novas concepções de temporalidade na música exigiram a transcendência da șimbologia gráfica tradicional e a instauração de novas tradições simbólicas para a notação musical. Setas, linhas, faixas, pontos e círculos são exemplos de uma infinidade de signos que entraram em uso nos meados do século passado, e que, desde então, ampliaram o vocabulário gráfico para o registro de sonoridades.

\footnotetext{
Não desconhecendo as argumentações de que uma gravação, ou mesmo uma efêmera execução musical possam ser consideradas texto, devemos esclarecer que, neste artigo, o que designamos "texto musical" é a informação escrita ou impressa.
} 
Justificam-se os novos "grafismos", principalmente, em função da plasticidade rítmica e da libertação do produto final de idéias completamente préconcebidas, reflexo de pontos de vista filosóficos que divergem do positivismo para o relativismo.

No que diz respeito às edições musicais, hoje eletrônicas, softwares específicos (Finale e Sibelius, por exemplo) acompanharam a evolução do repertório de símbolos gráficos para a notação musical. Quando novos símbolos não se encontram nas bibliotecas desses programas, eles dispõem de ferramentas que possibilitam sua criação e armazenamento. O acabamento das edições eletrônicas, e a sua praticidàde em termos de arquivamento, preservação da informação e transferência a usuários, tornaram-nas praticamente indispensáveis. Os compositores já não distribuem suas obras via manuscritos, como se fazia anteriormente, ficando a escrita eventualmente restrita aos rascunhos e processos pré-composicionais. Não somente o hábito de ler manuscritos já é incomum dentre os intérpretes, quanto, a julgar pelos exercícios nas classes de composição (raramente entregues em manuscritos!), a "caligrafia" musical não vem se desenvolvendo entre os jovens compositores.

Nesse caso, sendo a escrita eletrônica - estereotípica por concepção - o meio de expressão direto do compositor, devemos refletir que sua formatação não deve ser um recurso atuante como um possível auxiliar na transmissão de idéias musicais. A nova geração de compositores, portanto, parece conceber a notação tendo em mente edições impressas.

Diferentemente, para muitos compositores da geração anterior, ${ }^{2}$ o manuscrito ainda era concebido, na maioria das vezes, como uma forma definitiva de expressão textual. No Brasil, as edições de partituras dos anos 70 e 80 , muitas delas realizadas pela FUNARTE e por universidades, ${ }^{3}$ publicaram manuscritos. Em cadernos de vários autores, nota-se, portanto, diversidade

\footnotetext{
2 Referimo-nos à geração, cuja atividade composicional desenvolveu-se entre as décadas de 1950 e 1980, especialmente nos países onde os recursos para a impressão musical sempre foram precários.

3 A "Série Compositores da Bahia", por exemplo, editada pela UFBA em parceria com o INM-FUNARTE.
} 
de estilos. Alguns compositores com habilidade profissional em desenho (como o baiano Agnaldo Ribeiro) fizeram cópias meticulosamente "esquadrejadas" para a finalidade da publicação de suas peças e de outros colegas, enquanto outros preferiram deixar a obra em sua caligrafia livre. Se observarmos, por exemplo, o volume 9 da "Série Compositores da Bahia", com obras para piano de Agnaldo Ribeiro, Ernst Widmer, Lindembergue Cardoso e Paulo Lima, vamos poder constatar a mencionada diversidade. As obras de Agnaldo Ribeiro e Paulo Lima mostram o mesmo estilo editorial, ${ }^{5}$ enquanto as obras de Ernst Widmer (Sonata para piano op. 122) e Lindembergue Cardoso (Relatividade II/ op. 82) se apresentam nas caligrafias musicais dos seus autores.

Estimulado pela euforia composicional da Bahia nos anos 70, o maestro Piero Bastianelli desenvolveu um estilo sofisticado e inconfundível de cópias semi-manuscritas, ${ }^{6}$ assim estimulando a publicação de partituras no âmbito da UFBA. Um dos últimos trabalhos editoriais de Bastianelli é o volume Lindembergue Cardoso - 31 peças para orquestra, coro, coro e orquestra, banda, música de câmera e obras didáticas (Salvador, UFBA, 1991). Essa coletânea se distingue das publicações antecedentes pelo fato de serem obras de um único autor apresentadas num único estilo caligráfico: um trabalho artesanal, onde a atenção aos detalhes traduz-se em qualidade e bom gosto. Perguntamo-nos o que revelaria uma observação comparativa das edições de Bastianelli com os manuscritos de Lindembergue Cardoso. Perguntamo-nos, também, em que sentido as cópias estilizadas são positivas ao trabalho do intérprete, e o que poderia acrescentar a uma interpretação a observação do texto manuscrito. Essas perguntas nos conduziram ao livro de Walter Ong Orality and Literacy: The Technologizing of the Word (cf. ONG,

\footnotetext{
${ }^{4}$ Cf. Ribeiro et al., 1985.

${ }^{5}$ Não temos dúvidas de que Agnaldo é o autor da cópia de Cuncti - Serenata op. 19 de Paulo Lima; a autoria da cópia não se encontra na edição.

"O uso de transferíveis, como os da marca "Letraset", concedeu um caráter hibrido às copias de Bastianelli.
} 
1982), ${ }^{7}$ no qual o autor discorre sobre as diferenças entre o pensamento e sua expressão nas culturas oral e escrita. Embora relativas a textos verbais em relação à oralidade, as idéias de Ong se aplicam igualmente à escrita musical em relação à performance.

No capítulo 4 ("Writing restructures consciousness"), Ong se atém à reestruturação do pensamento pela escrita, que ele considera uma tecnologia, assim como o são a imprensa e o computador. "A escrita é, de certa forma, a mais drástica das três tecnologias. Ela inicia o que a imprensa e os computadores somente continuam: a redução do som dinâmico ao espaço quiescente", da linguagem oral-aural à visual, portanto. ${ }^{8}$ Para Ong, "a escrita conscientiza mais do que qualquer outra coisa", ao nos isolar do meio social. Escrever, portanto, é uma operação solipsística. ${ }^{9}$

A necessidade de precisão da linguagem, decorrente da distância entre os interlocutores, aguça o senso de análise lingüística e acaba gerando os grafoletos, as gramáticas, os dicionários que separam cada vez mais a escrita da língua materna - a usada pelas mães na educação das crianças. Há, portanto, uma perda de "presença" na expressão escrita, e essa mesma perda se revela igualmente na passagem do manuscrito à cópia impressa. No entanto, diz Ong, "a tecnologia, propriamente interiorizada, não degrada a vida humana, mas, ao contrário,

\footnotetext{
7 Pe. Walter Jackson Ong, Ph.D. (Kansas City, Missouri, 1912 - 2003) foi professor de Humanidades (Literatura Inglesa, História cultural e religiosa) na Universidade de Saint Louis (Missouri). Em Orality and Literacy: The Technologizing of the Word, o autor trata das diferenças entre o pensamento e sua expressão nas culturas oral e escrita. Traduzido para o português sob o título Oralidade e cultura escrita: a tecnologização da palavra (Trad. Enid Abreu Dobránszky), o livro de Ong se encontra publicado no Brasil pela Papirus (Campinas, SP, 1998). As citações neste artigo se derivam do original em língua inglesa, sendo nossa a tradução.

${ }^{8}$ "Writing is in a way the most drastic of the three technologies. It initiated what print and computers only continue, the reduction of dynamic sound to quiescent space, the separation of the word from the living present, where alone spoken words can exist." (cf. ONG, 2002).

9

"Technologies are not mere exterior aids but also interior transformations of consciousness and never more than when they affect the word. Such transformations can be uplifting. Writing heightens consciousness. Alienation from a natural milieu can be good for us and indeed is in many ways essential for full human life. To live and to understand fully, we need not only proximity but also distance. This writing provides for consciousness as nothing else does." (cf. ONG, 2002).
} 
enobrece-a." $^{10} \mathrm{E}$ no desdobramento ilustrativo dessa frase, ele faz uma razoavelmente extensa digressão sobre as tecnologias da performance musical em instrumentos acústicos ou eletrônicos, para concluir que "a escrita é uma tecnologia muito mais profundamente interiorizada do que o é a execução da música instrumental"; e que "o uso de uma tecnologia pode enriquecer a psyche humana, engrandecer o espírito humano, intensificar a vida interior". "Essas considerações de Ong - o aspecto reducionista da escrita, a reestruturação da consciência pela escrita, a interiorização que a escrita estimula, a perda de presença autoral na escrita e, em maior grau, na escrita impressa - conduziram as reflexões elaboradas neste artigo.

Há quase nove anos coordenamos uma pesquisa - "Marcos Históricos da Composição Contemporânea na UFBA" -, cuja principal produção converge para a edição eletrônica de partituras acompanhadas de comentários analíticos. $\mathrm{Na}$ preparação das partituras em Finale, diversos bolsistas de "Apoio Técnico" (CNPq) vêm atuando sob orientação editorial. Temos atualmente 17 obras de diferentes compositores da UFBA publicadas e disponibilizadas no site da pesquisa, ${ }^{12}$ cuja maioria data das décadas de 1960 e 1970. No ano de 2008, iniciamos a publicação de obras da década de 1980, e para tanto selecionamos duas composições de Ernst Widmer: Jahrestraumzeiten (As 4 Estações do Sonho op. 129, 1981), para duas flautas solistas e orquestra de cordas; e Sertania, Sinfonia do Sertão (op. 138, 1982-83). O estudo analítico dessas duas obras recomendou a edição eletrônica de Sertania. Entretanto, no que diz respeito a Jahrestraumzeiten, admitimos que a edição fac-similar do manuscrito hológrafo ${ }^{13}$ seria mais recomendável.

\footnotetext{
10 "Technology, properly interiorized, does not degrade human life but on the contrary enhances it." (cf. ONG, 2002).

11 "The use of a technology can enrich the human psyche, enlarge the human spirit, intensify its interior life. Writing is an even more deeply interiorized technology than instrumental musical performance is." (cf. ONG, 2002).

${ }^{12}$ Cf.: <http://www.mhccufba.ufba.br/publicacoesProjetos.php?serie $=1>$.

13 Inteiramente escritos à mão pelo autor e signatário, os manuscritos hológrafos se distinguem dos autógrafos, cuja autoria, identificada por assinatura, poderá não ser a do autor do documento.
} 
Quais os prós e os contras de edições eletrônicas? Por que certos textos musicais recomendam sua edição e outros não? Procurando responder essas duas questões, apresentamos, sucintamente, os dois estudos de caso acima mencionados. Em cada um, apontamos as observaçōes analíticas que conduziram as decisões de manter o manuscrito original ou de editá-lo.

\section{Jahrestraumzeiten: os prós do manuscrito e os contras da edição eletrônica}

Jahrestraumzeiten (As 4 Estações do Sonho) é uma obra de um compositor aos 54 anos de idade e 31 anos de carreira profissional. Na folha que serve de capa ao manuscrito hológrafo, ele informa que a motivação foi uma encomenda do Conselho Administrativo da Lei do Fomento à Cultura do Cantão de Aargau. ${ }^{14}$ Nessa mesma folha, a obra é apresentada como:

4 pequenos poemas sonoros concertantes, para serem tocados isoladamente, em pares, a três ou [a série] completa, em qualquer seqüência: Primavera-verão-outono-inverno, como em Vivaldi e Haydn; Outono-inverno-primavera-verão, como no hemisfério sul; Inverno-primavera-verão-outono, de acordo com ano civil nórdico; verão-outono-inverno-primavera, de acordo com o ano civíl do hemisfério sul. (Widmer, 1981, tradução nossa).

$\mathrm{Na}$ informação, portanto, o compositor se refere a uma ideologia estrutural que vincula a obra a um programa eminentemente narrativo, descritivo, paisagístico: as estações do ano, e suas diferentes seqüências, de acordo com o local em que sejam experienciadas: o hemisfério norte ou sul. No verso dessa mesma folha, Widmer apresenta uma outra face da concepção ideológica da obra, ou seja, um programa análogo:

${ }^{14}$ Kuratorium zur Förderung der Kultur im Kanton Aargau. 
Jahrestraumzeiten (estações do sonho) ou Jahresumzeiten (estações fora de época) enfatizam os paradoxos que acompanham o ciclo original de tornar-se, ser e morrer: assim, a primavera é um novo acordar e tristeza; verão é zênite e chuva morna; outono, maturidade e ímpeto; inverno, reflexão e suaves colinas nevadas e ensolaradas. Assim, todas as estações são transições sem fim, e cada uma está contida em todas as outras: mutações que, observadas nos trópicos, ganham a dimensão do sonho e, principalmente, apresentam sua continuidade irreversível de forma translúcida. (Widmer, 1981. tradução nossa).

A obra, portanto, se refere ao ciclo da natureza no planeta terra, e também às diferentes fases da vida. A “dimensão do sonho", mencionada nas notas explicativas e no título, pode ser compreendida como a dimensão de uma realidade distante: a da sua origem nórdica e alpina, a qual ele tenta incorporar, por meio de impressões sonoras, em sua expressão musical já bastante impregnada de "brasilidade". ${ }^{15}$ O programa das estações transcende, portanto, o simples significado paisagístico, para incorporar a dimensão complexa dos intercâmbios de características e da "convivência" de opostos.

Paisagens sonoras evocativas são tanto evidentes quanto significativas em Jahrestraumzeiten. Pode-se notar que a intenção "pictórica" da obra já se evidencia nos desenhos que o compositor fez para as capas de cada movimento (ver Figs. 1). ${ }^{16}$

A evocação paisagística é musicalmente concebida com efeitos tímbricos: por exemplo, sons débeis dos harmônicos em "Inverno"; figurações em col legno batt. ou com cordas friccionadas atrás do cavalete em "Outono"; glissandi de flauta em "Primavera". Nesses momentos, podese observar que a notação manuscrita tem funcionalidade na intensificação da sugestão paisagística.

\footnotetext{
${ }^{15}$ Em Jahrestraumzeiten, essa "brasilidade" se reflete principalmente num trabalho motívico que tem origem na tradição musical folclórica do Nordeste, com țípico "sabor" modal.

${ }^{16}$ Tratando-se de uma estrutura aberta, os quatro movimentos da obra são apresentados em quatro partituras independentes.
} 

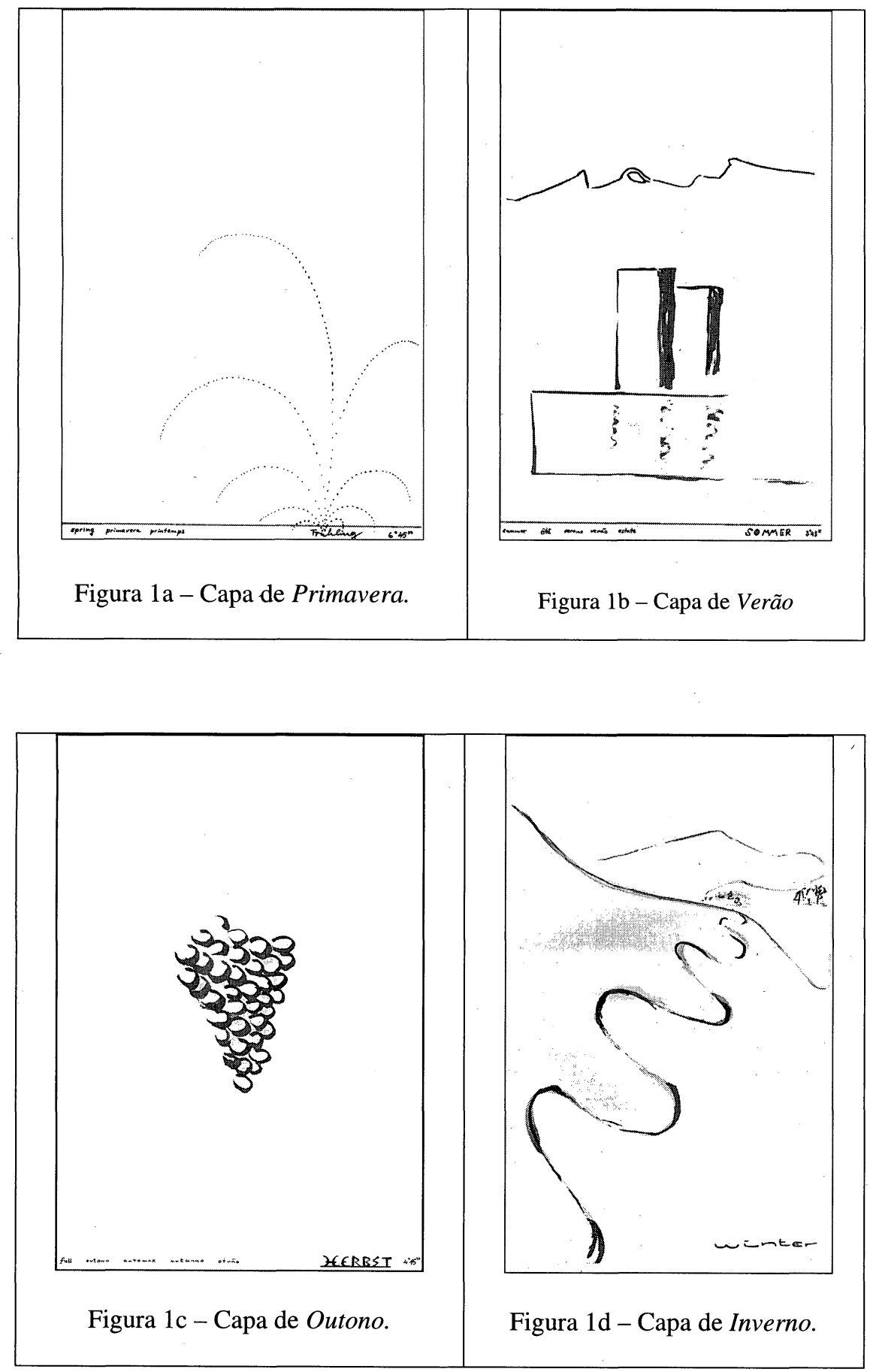
Em "Primavera", após a grande pausa do compasso 36 (cf. Fig. 2), cujo significado expresso nas notas que acompanham a partitura é "Pausa do pressentimento" (Ahnungspause), a suspensão da notação métrica para incluir a sugestão do canto do pássaro (fl. 1) entre os compassos 37 e 39 é um desses trechos em que a notação manuscrita se reveste de um alto grau de sugestibilidade. O design especialmente concebido para as cordas soli alternando, individualmente, efeitos col legno e pizz., parece justificar-se antes no aspecto visual do que no efeito sonoro; considerando a pequena faixa de registro dos instrumentos em conjunto - Sol2 - Si3 - e os conteúdos de alturas distribuídos por instrumento, vemos que a ordem das entradas correspondeu antes a uma concepção visual do que sonora (outras ordens teriam resultado em efeito muito similar, de distinção irrelevante para a configuração da textura sonora). As ligaduras sinuosas entre pautas relacionando os motivos diádicos simplesmente reforçam o traçado angular; a forma de indicar a repetição motívica (com seqüências de sinuosas e pontos em número correspondente ao número de reiterações), a distribuição das dimensões temporais das repetições motívicas e a grande sinuosa interrompida relacionando os finais dessas repetições, todos esses aspectos colaboram para a configuração de uma idéia visual sugestiva, ${ }^{17}$ iconográfica, cuja concepção é própria do "desenho à mão livre". Sua reprodução numa edição eletrônica certamente se ressentiria da forte "presença autoral" impregnada na escrita dessa passagem. O acesso ao manuscrito, indiscutivelmente, é o que permite a nítida percepção da intenção, do espírito e da energia emanada da escrita do compositor.

\footnotetext{
17 Propositadamente, isento-me de definir a sugestibilidade do texto, deixando-a à percepção do leitor.
} 


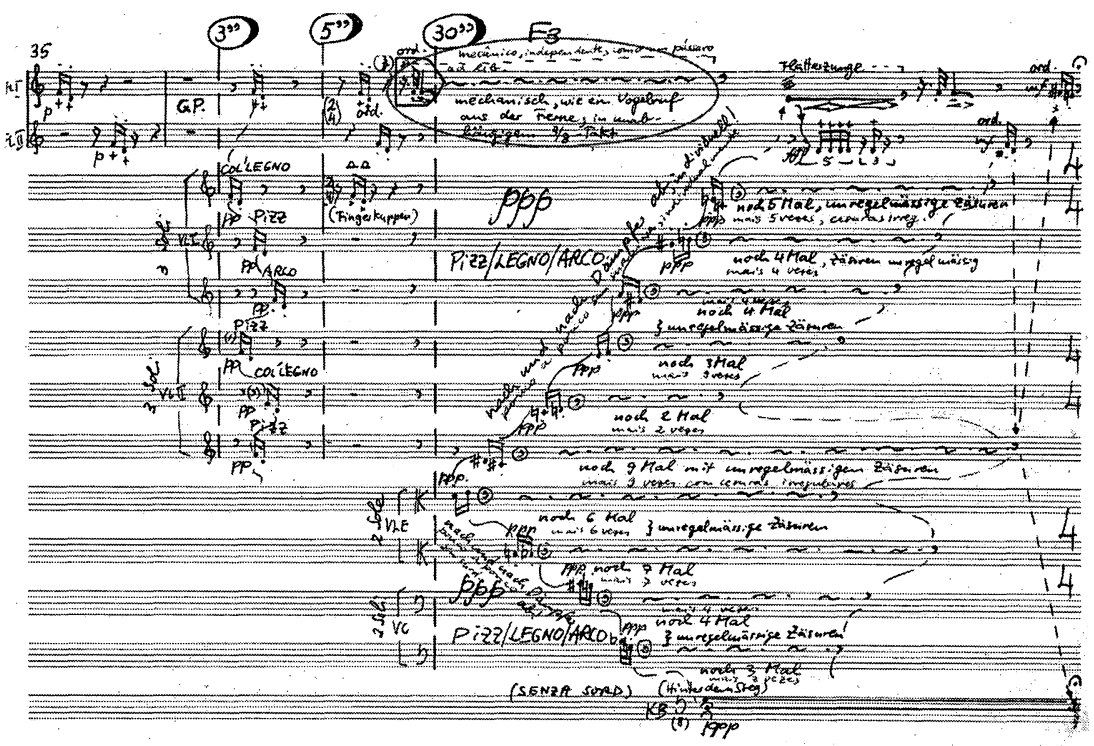

Figura 2 Ernst Widmer, Jahrestraumzeiten - Frühling (Primavera), compassos 35-39

Poderíamos até mesmo compreender uma relação um tanto explícita entre a delicada sonoridade concebida para a sugestão paisagística do exemplo da Figura 2, a leveza da notação escolhida para indicar as repetições e vinculações no trecho (pontos, pequenas sinuosas, curvas com traços interrompidos), e a iconografia com que o compositor ilustra a primavera na capa do manuscrito que corresponde a esta estação (cf. Fig. 1a).

Em "Inverno", as grandes ligaduras, traçadas entre as duas flautas solistas (Fig. 3), têm a função de assegurar que a alternância dos instrumentos seja realizada de acordo com a concepção de um diálogo monológico (ou de um monólogo dialógico). $^{18}$ No entanto, não podemos também deixar de perceber que, na continuidade irregular e espontânea com que se encontram configuradas na escrita, essas amplas sinuosas sugerem as "suaves colinas nevadas e ensolaradas" (sanfte Schneesonnenhalden), uma das idéias com que o compositor concebeu essa estação.

\footnotetext{
${ }^{18}$ Nas notas que acompanham a partitura, o compositor diz que o concerto duplo tem a finalidade de "esgotar as várias possibilidades da transição do monólogo ao diálogo" ("[...], um die viele Möglichkeiten des Ubergangs von Monolog zu Dialog auszuschöpfen").
} 
Outra vez, pode-se compreender que essa impressão sugerida na espontaneidade da grafia manuscrita venha a perder em “presença” numa edição eletrônica.

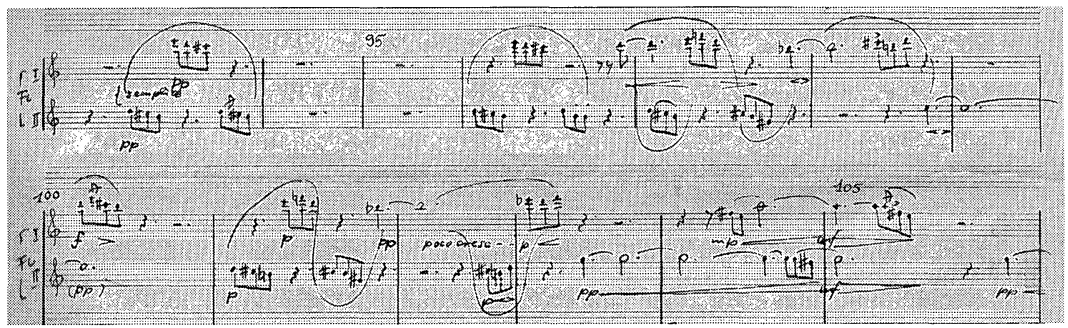

Figura 3 Ernst Widmer, Jahrestraumzeiten - Winter (Inverno), compassos 93 - 105, flautas 1 e 2

Sem dúvida, pode-se também aqui compreender uma relação ainda mais explícita entre as ligaduras inversas articuladas com que o compositor associa as duas flautas solistas e a grande sinuosa em perspectiva na capa do movimento "Inverno" (cf. Fig. 1d).

Em "Outono", chamo atenção para a sugestão de ímpeto na escrita "à mão livre" das figurações em glissando col legno batt. jeté distribuídas entre dois violoncelos e contrabaixo (cf. Fig. 4). A caracterização do traçado ascendente irregular dessas figuras, bem como a distribuição espacial da sua reprodução continuada (imitativa), são visualmente expressivas, evocativas, sugerindo a ação do vento outonal. Aqui não se trata de uma notação icônica, mas de uma escrita com características indiciais. A observação da escrita original nos conduz a refletir sobre a intenção composicional em tornar o trecho mostrado na Figura 4 visualmente conotativo, sugerindo uma performance plasmada pela escrita.

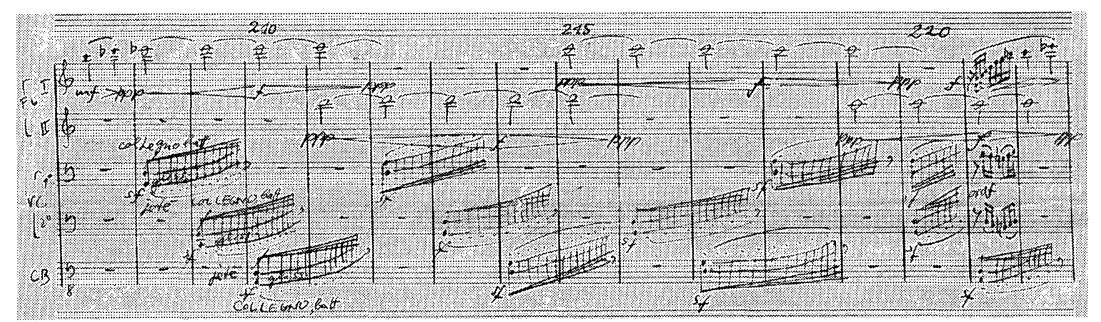

Figura 4 Ernst Widmer, Jahrestraumzeiten - Herbst (Outono), compassos 207-222 
Os três exemplos musicais mencionados correspondem a objetos sonoros com função "representativa" no sistema acústico da obra; a idéias musicais cuja origem remonta ao paisagismo, ao plano visual. Em sua notação, observa-se que a escrita transcende o aspecto simbólico (do signo instituído, convencionalizado) e sua função primária, isto é, prescritiva (fonte de instruções para a recriação da música). Os conjuntos sígnicos observados parecem ter sido concebidos com o intuito de também exercerem uma função icônica (em Primavera e Inverno) ou indicial (em Outono). Estamos aqui, portanto, diante de conceitos básicos à filosofia da linguagem de Charles Sanders Peirce - a tríade símbolo/ícone/índice -, ${ }^{19}$ para compreendermos a funcionalidade de uma escrita musical que se evidencia como figurativa, poética, iconográfica.

A notação de Jahrestraumzeiten serve, portanto, como argumento contrário à afirmação que reproduzimos na introdução deste artigo - "o texto musical é mera fonte de instruções para a recriação da música". O manuscrito de Widmer ilustra como o texto musical pode aderir significativamente aos objetos sonoros que representa graficamente - a textura tímbrica de Primavera, a linearidade articulada de Inverno e a imitação motívica de Outono-, constituindo estruturas multidimensionais, onde se observa a combinação interativa de signos simbólicos, indiciais e icônicos. A compreensão da plena funcionalidade de um texto musical com tais características requer, portanto, uma abordagem semiológica, para a qual o acesso ao manuscrito hológrafo, com todas as suas nuances significativas, é fundamental.

\footnotetext{
${ }^{19}$ Convém aqui lembrar a tipologia triádica dos signos de Peirce (cf. Peirce 1909), que compreende ícones, índices e símbolos. A distinção entre esses três tipos se encontra fundamentada nos princípios de semelhança física, correlação de contiguidade e relação convencionada entre significante e significad́. Ícones são signos que têm uma semelhança física (analógica) com o "objeto" que eles representam; índices se definem por uma correlação em tempo ou espaço, com o seu significado; e símbolos são signos instituídos. convencionalizados; independes de semelhança física ou de correlação de qualquer natureza com o objeto representado, sua identificação requer o conhecimento da convenção que os associa aos seus significados. Vale também salientar que a identificação de um signo como ícone ou índice nem sempre é clara, sempre requerendo alguma reflexão, pois todo ícone tem um matiz indicial, assim como todo índice tem algum valor icônico.
} 


\section{Sertania: os contras do manuscrito e os prós da edição eletrônica}

Ao contrário do que se verifica em Jahrestraumzeiten, a partitura de Sertania exemplifica o caso em que o manuscrito deixa claros indícios da necessidade de uma edição crítica. $^{20}$ Concebida para orquestra sinfônica com adição de uma voz solista (soprano) e violão, ${ }^{21}$ o manuscrito se encontra em papel tamanho A3 com 32 pentagramas. Enumero abaixo os diversos aspectos que recomendaram a edição eletrônica.

Espacializacão: Com várias subdivisões das cordas, e individualizando bastante as partes instrumentais nos naipes dos sopros, a partitura manuscrita de Sertania se apresenta densa e compacta em trechos de tutti, ao ponto de se tornar confusa. A flexibilidade na distribuição das pautas que a escrita eletrônica oferece é, nesse caso, uma vantagem no aspecto da clareza. Tanto se pode reduzir o número de pautas nas páginas de pequena densidade orquestral, como multiplicá-las ao que seja necessário para a clara inteligibilidade da escrita. A edição eletrônica clarificou a escrita para os naipes dos sopros e também das cordas, nas múltiplas subdivisões.

Acidentes "de precaução": Outro aspecto notado na obra foi um excesso de acidentes "de precaução"; sua racionalização na edição crítica foi recomendável. A edição eletrônica de Sertania eliminou uns tantos acidentes e colocou parênteses em muitos outros, em função de consistência, de uma escrita menos densa em sinais, e mais "profissional".

\footnotetext{
${ }^{20}$ Realizada nos anos de 2007-2008, a edição crítica de Sertania, junto ao estudo analítico dos aspectos de simbologia sonora e paisagismo musical, encontra-se como o $17 .^{\circ}$ volume da série "Marcos Históricos da Composição Contemporânea da UFBA".

21

Orquestra de Sertania: 2. 2. 2. 2 / 3. 3. 3. 1 / perc.(6), voz (S), pf., vlão. / cordas.

${ }^{22}$ Não queremos insinuar que o compositor, na maturidade dos seus 56 anos de idade e 33 anos de atividade profissional, desconhecesse a escrita profissional. Ponderamos, entretanto, que, ao contrário de Jahrestraumzeiten, cuja partitura manuscrita deve ter sido cuidadosamente revista em função do envio ao órgão público da Suíça que encomendou a obra, Sertania teve uma finalidade imediata "doméstica": servir à trilha sonora do desenho animado "Boi Aruá", de Francisco Liberato de Matos. Em função da grandiosidade da obra (no que pesam tanto instrumentação quanto a duração), uma revisão cuidadosa deve ter sido adiada ao ponto de nunca ter podido se concretizar.
} 
Organizacão da grade orquestral: Outro ponto que recomendou a edição crítica foi a organização da percussão na grade. Praticamente a cada página, a ordem dos 6 percussionistas mudava. Em uma determinada cópia heliográfica do manuscrito hológrafo, pudemos verificar a distribuição da percussão indicada com lápis vermelho, evidenciando, claramente, que foi realizada posteriormente à confecção do manuscrito definitivo. ${ }^{23} \mathrm{Na}$ edição eletrônica, ordenamos a distribuição da percussão, facilitando a leitura.

Inconsistências e ambigüidades: Em certos trechos, a notação sígnica se evidenciou confusa, requerendo re-configuração para a transmissão de uma informação inequívoca. Inconsistências e ambigüidades nos pareceram justificadas por economia de meios, em virtude de insuficiência de espaço na página. Nos casos em que a concepção notacional do compositor nos pareceu ambígua, valemo-nos da gravação (regida pelo compositor) ${ }^{24}$ e da consulta a músicos intérpretes da mesma, no sentido de "conferirmos" nossa interpretação da notação utilizada. ${ }^{25}$ Vejamos alguns exemplos onde a concepção da notação foi alterada em função de uma informação mais precisa.

No $3^{\circ}$ movimento, compassos $46-49$, a notação do piano no manuscrito hológrafo é a da Figura 5:

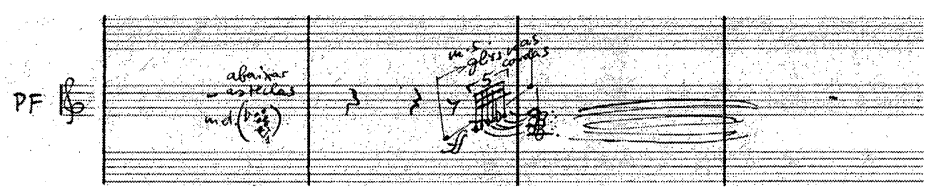

Figura 5 Ernst Widmer, Sertania, extrato do manuscrito hológrafo: $3^{\circ}$ movimento (c. 46-49)

\footnotetext{
${ }^{23}$ Tivemos a informação de um músico intérprete da gravação de Sertania, de que a distribuição da percussão teria sido um "exercício" para alunos de composição de Widmer. ${ }^{24}$ Ernst Widmer - Sertania - Sinfonia do Sertão. Rio de Janeiro: Polygram do Brasil. LP WE 01, 1983.

${ }^{25}$ As modificações que realizamos na escrita de Widmer foram discutidas com intérpretes e compositores. Nesse sentido, somos gratos ao compositor e musicólogo Dr. Pablo Sotuyo, ao maestro e pianista Eduardo Torres, e ao percussionista Oscar Mauchle, pelas respectivas colaborações.
} 
Interpretando que a quiáltera da mão esquerda reflete o efeito resultante dos abafadores suspensos nas cordas correspondentes às teclas abaixadas da mão direita, modificamos a notação desse trecho da seguinte forma:

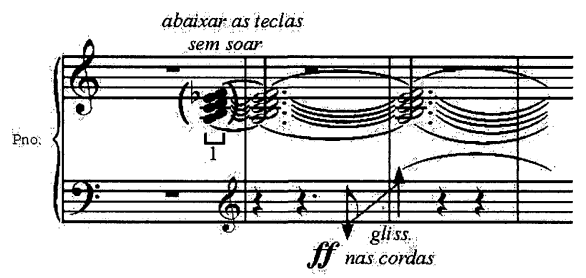

Figura 6 Ernst Widmer, Sertania, extrato da edição eletrônica: $3^{\circ}$ movimento (c. 46-49)

Também no $3^{\circ}$ movimento, compasso 6 , a notação dos sopros no manuscrito hológrafo é a da Figura 7:

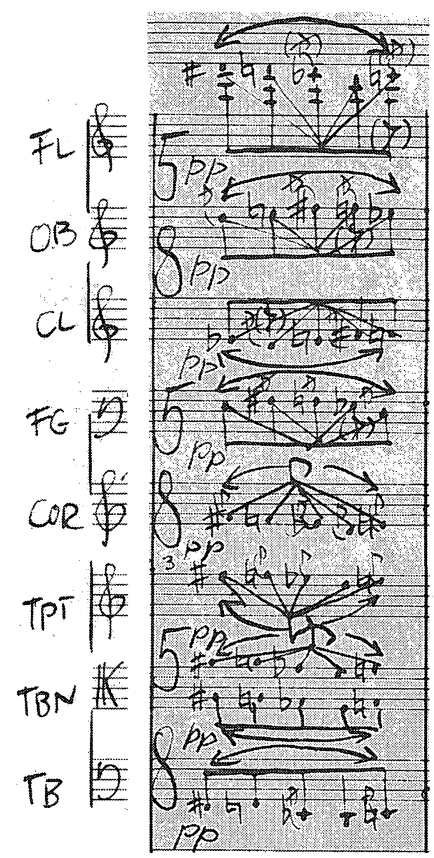

Figura 7 Ernst Widmer, Sertania, extrato do manuscrito hológrafo: $3^{\circ}$ movimento (c. 6) 
Nos compassos seguintes (7 e 8), sinais de repetição (sinuosas e pontos, como se encontra nas cordas da Figura 2) indicam a continuidade repetitiva do motivo de 5 colcheias. Notando inconsistência na notação dos instrumentos que realizam o mesmo design motívico, procuramos analisar o trecho dos compassos 6 a 8 com o auxílio da gravação; isso não nos ajudou, pois não se distingue os instrumentos isoladamente na massa textural. Com base na notação do motivo análogo apresentado anteriormente (c. 3, cf. Fig. 8), entendemos que a função das duas setas nas ligaduras da Figura 7 seria indicar que a continuidade da repetição motívica (c. 7 e 8) deve se realizar com a alternância de duas leituras do motivo: na ordem escrita imediatamente seguida pela retrógrada. A inconsistência da notação encontrada entre os compassos 3 (Fig. 8) e 6 (Fig. 7) estaria justificada pela falta de espaço suficiente, na densidade instrumental do compasso 6.

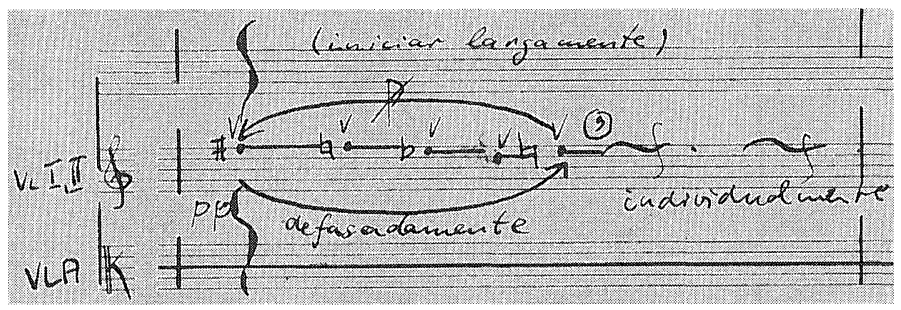

Figura 8 Ernst Widmer, Sertania, extrato do manuscrito hológrafo: $3^{\circ}$ movimento (c. 3)

Tentemos agora interpretar outro aspecto incongruente na notação do compasso 6 (Fig. 7), onde a escrita da tuba e do trombone 2 nos pareceu clara. Para o restante dos metais, pode-se argumentar que as linhas oblíquas dirigindose das cabeças das notas para a colcheia central foram um artifício ditado pela falta de espaço suficiente. No entanto, na escrita das madeiras, não conseguimos justificar a manutenção das linhas oblíquas junto às hastes verticais; na obra de Widmer (cuja maior nos é familiar) e do Grupo de Compositores da Bahia, desconhecemos outro exemplo desse tipo de notação. Cremos que não conseguimos um entendimento definitivo, e elegemos a notação do motivo na tuba como fator de consistência para a escrita do compasso 6 (cf. Fig. 9); por 
prudência, decidimos incluir a notação manuscrita dos sopros nesse compasso numa "Nota editorial". Considerando o efeito ouvido na gravação, nossa reescritura dos sopros no compasso 6, tal qual se encontra na Figura 9, pode ser considerada "aplicável".

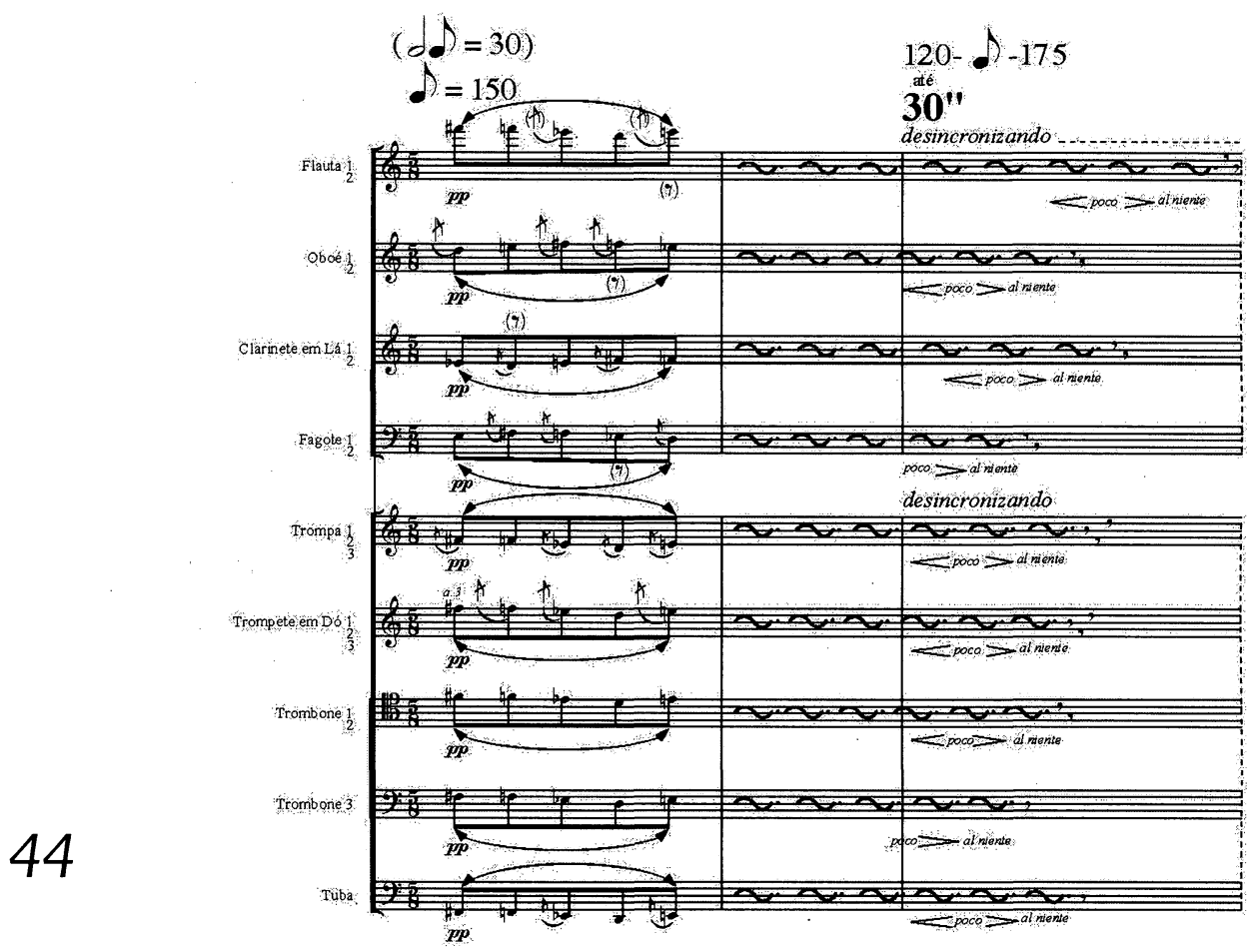

Figura 9 Ernst Widmer, Sertania, extrato da edição eletrônica: $3^{\circ}$ movimento (c. 6)

\section{Considerações conclusivas}

Podemos dizer que os dois estudos de caso apresentados se aplicam à verificação de como as reflexões de Walter Ong sobre a escrita verbal dizem igualmente respeito à notação musical. Se, como diz o autor, a escrita estimula a consciência, analisar a notação de um compositor permite, portanto, a observação do nível de conscientização na concepção musical. Quanto à afirmação de que há uma notável perda de "presença", de "autoridade", na passagem do manuscrito à cópia impressa, se considerarmoś que alguns 
compositores parecem escrever tendo em mente edições impressas, devemos admitir que essa "presença" adicional nos manuscritos musicais não é generalizável. Os dois estudos de caso também nos levam a admitir que nem todos os manuscritos de um mesmo compositor revelam, de igual maneira, sua "presença". Assim podemos dizer da presença de Ernst Widmer nos dois manuscritos que analisamos. Ambas as obras são igualmente circunscritas a programas paisagísticos, e ao mesmo tempo psicológicos (Jahrestraumzeiten) e sociológicos (Sertania). No entanto, enquanto o argumento de Jahrestraumzeiten tem reflexos numa notação iconográfica, que, a depender da percepção do leitor, poderá servir de estímulo a um vôo de fantasia, o mesmo não se percebe em Sertania, onde os objetos musicais (motivos, temas, padrões rítmicos, texturas), independentemente da configuração notacional, refletem o programa da obra.

No primeiro caso, temos o exemplo de um texto alusivo, onde, por trás dos elementos prescritivos, há um mundo mais sutil, que se revela na maneira em que os elementos são espacializados, direcionados, configurados com maior ou menor grau de espontaneidade, irregularidades e imprecisões. Além de instruções, há na partitura uma dose de sugestibilidade, cuja compreensão, repetimos, depende da capacidade perceptiva do músico. O estudo da partitura de Jahrestraumzeiten nos conduz de um mundo sensorial fundamentado na audição para um outro baseado na visão, e vice-versa.

No segundo caso, temos uma partitura altamente prescritiva, na qual o compositor é minucioso com o detalhamento de articulações, dinâmica e timbre, por vezes indicando as cordas em que uma passagem deve soar, ou até mesmo onde o instrumentista de sopros poderá respirar. No entanto, em nenhum momento a escrita se revela impregnada do programa da obra. Considerando-se também a notação confusa, ambígua e inconsistente em Sertania, admitimos, neste caso, que a edição eletrônica substitui, com vantagens, o manuscrito hológrafo. 


\section{Referências}

PEIRCE, Charles Sanders. A Sketch of Logical Critics (1909). In: The Essential Peirce. Selected Philosophical Writings. (1893-1913). Bloomington and Indianapolis: Indiana University Press, Peirce Edition Project, 1998. v. 2. p. 460-461.

ONG, Walter J. Orality and Literacy: The Technologizing of the Word. London and New York: Methuen, 2002 [1982]. Parts of Chapter 4 (Writing restructures consciousness). p. 77-94, 113114. Disponível em: <http://www.cs.indiana.edu/ port/teach/relg/ong.html>. Acesso em: 17 jun. 2009.

. ONG, Walter J. Orality and Literacy: The Technologizing of the Word. London and New York: Methuen, 1982.

RIBEIRO, Agnaldo et al. Obras para piano. Salvador: Gráfica Universitária, 1985. v. 9. (Série Compositores da Bahia).

WIDMER, Ernst. Sertania - Sinfonia do Sertão op. 138. 1983. 1 Partitura, manuscrito hológrafo. . JahresTRAUMzeiten. 1981. 1 Partitura, manuscrito hológrafo.

Ilza Nogueira: nogueira.ilza@gmail.com

Recebido e aprovado em 02 de março de 2009 